Chapter 4

\title{
Tailoring of Architecture and Intrinsic Structure of Electrospun Nanofibers by Process Parameters for Tissue Engineering Applications
}

\section{Dorota Kołbuk}

Additional information is available at the end of the chapter

http://dx.doi.org/10.5772/64177

\begin{abstract}
Electrospinning process is commercially used to form nanofibers as scaffolds in tissue engineering. Similarities in morphology of electrospun nanofibers to the natural extracellular matrix, flexibility, and low cost of the process contribute to their use in regeneration of cartilage, ligaments/tendons, muscles, and bones. Required properties are tailored by the use of appropriate polymers: polyesters, their copolymers, blends with natural biopolymers such as gelatin, collagen, chitosan, or composites with nanoparticles.

In the case of one component fibers, factors strongly influencing the final diameter of the electrospinning jet include volumetric charge density, distance between the needle and thecollector, needlediameter, and viscosity. A moderateeffect is exerted by initial polymer concentration, solution density, electric potential, and solvent vapor pressure.

In the case of blend fibers, the $\mathrm{w} / \mathrm{w} \%$ ratio of mixed polymers is an additional parameter of the electrospinning process. Addition of gelatin, collagen, and/or chitosan influence the solution properties and, in consequence, fiber diameter, mechanical properties, wettability, chemical structure, crystallinity, etc. Cellular response depends on electrospun fibers' tailored morphology, chemical structure as well as mechanical properties.

Electrospinning process is one of the success stories in nanotechnologies during the last few years. Understanding of electrospinning process parameters enables tailoring of electrospun nanofibers morphology, internal structure, and properties to appropriate application. This opens up new possibilities in tissue engineering.
\end{abstract}

Keywords: electrospinning, tissue engineering, collagen, chitosan, gelatin, polyester, nanofibers, scaffold 


\section{Introduction}

Natural and synthetic fibers have been used commonly in many applications. Silk, cotton, cellulose fibers have been used in textile industry and in regenerative medicine. Fibers and patches obtained by melt spinning, solution wet spinning, solution dry spinning, dry-jet wet spinning, gel spinning, phase separation spinning, reaction spinning are performed in diameter from nano to hundreds microns [1].

Electrospinning is one of the most common methods of nanofiber formation for the purposes of life science, protective clothing, filters, nanosensors, tissue engineering, drug delivery systems, and other applications. Synthetic and natural polymers, their blends, and composites with appropriate nanoparticles are used in the electrospinning process to form nano and submicron fibers with architecture and properties suitable for appropriate applications [2]. Fibers formed in the electrospinning process are used in tissue engineering, regeneration of cartilage, ligaments/tendons, muscles, and bones. Generally, the polymer and bioactivator used in the electrospinning process determine application in a suitable direction.

About 30 different parameters influence transformation of a polymer solution into electrospun nanofibers $[3,4]$. These parameters include (a) the solution properties such as viscosity, conductivity, and surface tension; (b) processing parameters such as the applied electric potential at the capillary tip and at the collector, distance between the tip and the collecting screen, solution flow rate; and (c) ambient parameters such as solution temperature, and humidity [5]. Due to many parameters, the electrospinning process is the most used multipurpose technique of nanofibers and patches formation.

In this chapter, we concentrate on nanofibers formed for tissue engineering applications. Langer and Vacanti in 1993 [6] defined tissue engineering as an interdisciplinary field that applies the principles of engineering and life sciences toward the development of biological substitutes that restore, maintain, or improve function (of tissue) or a whole organ. Ideally, a fibrous patch should mimic the shape and functionality of the native extracellular matrix (ECM) [7]. Scaffolds formed in the electrospinning process show great potential to provide ideal microenvironments for growth and proliferation of various kinds of cells. Synthetic, natural polymers and their blends are used for electrospinning to combine advantages of both components. Electrospinning patches show various morphology, architecture, surface, and mechanical properties, which have strong influence on cell growth, spreading, activity, and functions [8].

It is widely described that the morphology of electrospun nanofibers strongly depends on the solution properties (determined by the type of polymer and solvent (for example, see [3, 4, 10]) and parameters of the process (applied voltage, flow rate, diameter of the needle (for example, see [11, 12]). Several studies describe the influence of the aforementioned parameters on the molecular structure. Crystallinity of poly( $\varepsilon$-caprolactone) (PCL) has been described to depend on the solvent type [13]. Investigations on poly(vinyl alcohol) (PVA) indicate an increase of the molecular orientation with an increase of the polymer molecular weight $(\mathrm{Mn})$ [14]. Still, only few publications show influence of applied voltage on crystallinity of polyest- 
ers used in tissue engineering. Investigations on cellulose nanofibers (collected on a static plate) indicate an increase of crystallinity, with a local maximum value, as a function of applied voltage [15]. Qualitative analyses of crystallinity and molecular orientation of electrospun polyacrylonitrile (PAN) and poly(lactic acid) (PLLA) nanofibers indicate changes depending on polymer concentration, rotation speed of the collector (drum), and thermal treatment. Surface properties, such as stiffness, strongly depend on the molecular structure. Recent reports of in-vitro studies suggest a relationship between cellular response and molecular structure $[16,17]$.

Naturally occurring polymers, such as collagen (Col), Gelatin (Ge) and chitosan (Chit), implanted into humans do not cause foreign body response so they are successfully used in tissue engineering [18]. Major drawbacks are poor mechanical properties and variable physical properties due to different sources of the protein matrices. Taking these criteria into account, a hybrid of a natural polymer, such as Col, Ge or Chit, and e.g. PCL, represents a biocompatible and degradable polymer [19]. Bicomponent nanofibers combine the advantages of both types of materials - natural and synthetic (mechanical properties and reproducibility).

Proteins like $\mathrm{Col}$ and $\mathrm{Ge}$ in fibres form simulate Col fibres in ECM. Chit is a semi-crystalline polysaccharide which demonstrates high similarity to glycosaminoglycan also in ECM [20]. Due to this resemblance they are considered as the main or partial additive in electrospun nanofibers for tissues regeneration and antibacterial wound dressings.

This chapter sums up the correlation between electrospinning parameters and nanofiber morphology, patch architecture, molecular, and supermolecular structure as well as mechanical properties influencing the cellular response during in-vitro study. It is not possible to refer to all the literature on this subject; however, we show possible ways of tailoring the aforementioned properties by process parameters. This review is concentrated on pure polyesters and bicomponent nanofibers with Ge or Col. Blends: PCL/Ge, PCL/Col were selected as those which are considered very prospective in regenerative medicine and used in 3D scaffolds, wound dressing, drug delivery systems [21, 22]. At the end of the chapter, we try to answer the question which parameters are critical in the electrospinning process from the point of view of the morphology, structure, and properties of nanofiber patches influencing their functionality in tissue engineering.

\section{Electrospinning process}

Rayleigh was the first scientist who observed and described the electrospray process [23]. He discovered that a droplet in high voltage splints into small droplets through voltage gradient. This effect is named as "Rayleigh's instability". Nowadays, Zeleny [24] and Dole [25] continued investigations of Rayleigh. Dozin noticed that droplets from the electric field resemble aerosols in their external look (superficies) and properties [26]. Finally, electrospinning process was developed as a result of investigations on the electrospray process. The interest in electrospinning increased significantly after patent publishing in 1934 [27], which 
described the formation of cellulose fibers. In 1990s, PET nanofibers were electrospun, outlining new directions of scientific investigations and applications [28, 29].

Yarin and Reneker analyzed physics of the process and modeled the impact of parameters of the process on the jet move and formed fibers morphology [30,31]. Those investigations enable understanding and controlling of the electrospinning process. Theoretical investigations of the electrospinning process were translated into use in nanotechnology, medicine, and texture industry by Kowalewski, Zussman, Wendorff, Ramakrishna and many others groups.

Every year, hundreds of publications and patents are published; according to Pubmed, for "electrospinning \& tissue engineering", number of publication increased from 35 in 2006 to 262 in 2015; for "electrospinning \& scaffolds", from 29 in 2006 to 235 in 2015 . According to available data [32], the highest number of issued patents is published in USA, China, South Korea, Japan, and Germany. It has hugely increased mainly in Europe (17\%) and South Korea $(7 \%)$. The top patent owners include companies such as DuPont (6\%) and Donaldson $(4 \%)$, and universities, with a major focus of the overall patent portfolio on the development of filtration media, methods, and apparatus. On the other hand, the process scale-up is still largely an issue even for electrospinning technologies, with a lot of space for further improvements. For example, from technological point of view, single length of fiber should be tailored/ guided. In this case, electrospinning process exhibits poor reproducibility and accuracy in the production stage [33].

The equipment for the electrospinning process consists of high-voltage power supply, syringe with polymer solution, pump with controlled flow, and collector. Figure 1 illustrates the schemas of vertical model of the setup.

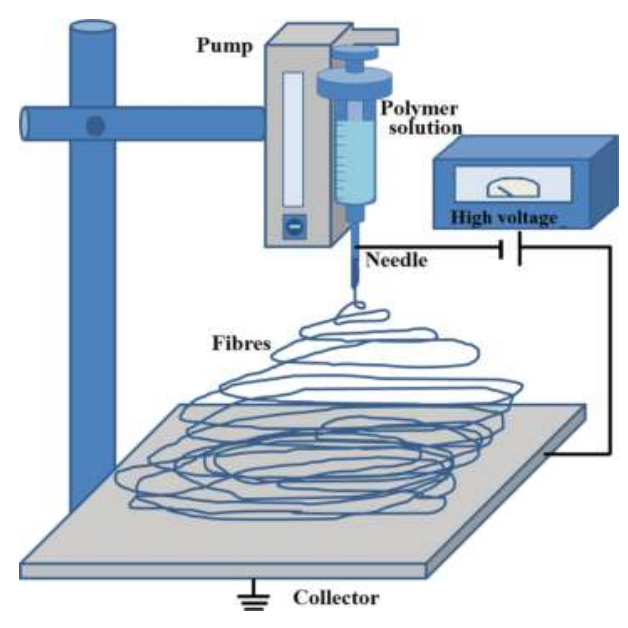

Figure 1. Schema of the process.

Depending on application, plates, drums, wires, or grids are used as the collector [10, 34]. To increase productivity of the process, multijet setups are used in industry and selected scientific 
labs [35]. Usually, home-made equipment is located in a laminar chamber, in rooms where temperature and humidity is controlled. Over the years, different methods of electrospinning have been considered: force spinning, multijet spinning, core-shell spinning, forcespinning, needleless-spinning, etc. (for example, see [10]).

The following companies offer commercial electrospinning supplies: Elmarco (www.elmarco.com), NaBond (www.electro-spinning.com), Holmarc Opto-Mechatronics (www.holmarc.com), E-Spin Nanotech (www.espinnanotech.com), Linari Engineering (www.linaribiomedical.com), Kato Tech (www.keskato.co.jp), Mecc Co. (www.mecc.co.jp), Toptec (www.toptec.co.kr), Electrospinz (www.electrospinz.co.nz), Electrospunra (www.electrospunra.com), IME Technologies (www.imetechnologies.nl), Yflow (www.yflow.com), and Inovenso (www.inovenso.com) [33].

\section{Fundaments of electrospinning}

Simplistically, high voltage is applied to the needle of the syringe with polymer solution. Electrostatic forces move the charges in the solution in the direction of the collector. Those forces exert effect on the solution droplet and deform it. Outflow of the solution (controlled by a dosing pump) and overrun of the critical value of the electrical field initialize flow of the solution into the collector. The solution is stretched under the high voltage into a thin jet. The solvent evaporates from the jet and formed fibers fall down on the collector [3].

Several steps can be distinguished during fiber formation in the electrospinning process (Figure 2):

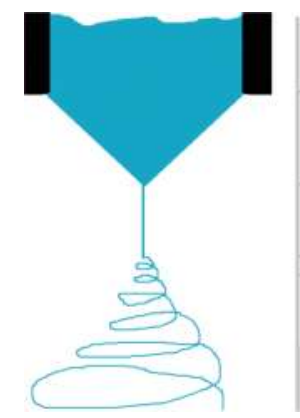

Solution jet in the needle

Taylor cone

Reclinear stream

Distabilities

Spiral zone

Figure 2. Zones during fibers forming in electrostatic field.

\subsection{The solution in the needle}

The first fiber forming zone, in the needle follows on initial orientation of the macromolecules solution to the transversal velocity gradient. In this case, the degree of orientation is determined by the ratio of the velocity gradient transverse to the rotational diffusion con- 
stant or the product of the gradient of the transverse flow rate of the solution and the relaxation time. Thus, the degree of orientation of the liquid jet leaving the needle increases with increasing flow rate and the length of the needle [36, 37].

\subsection{Taylor cone}

A drop of the solution after leaving the needle is exposed to an electrostatic field and takes the shape of a cone. Charge of the electric field is balanced by the forces of surface tension of the solution that changes it from a drop into a spherical cone. It creates a so-called Taylor cone at an angle of 49.3 degrees [38]. By the action of the electrostatic field, charges accumulated on the surface of the cone of the solution coexist with a higher charge density at the tip of the cone. The charge on the tip of the cone increases until exceeding the critical value at which the polarization reaches a value in excess of energy surface tension of the solution. The density of the charge at the top of the Taylor cone, which balances the surface tension of the polymer solution, is called the critical polarization $V c$. After exceeding the critical value of polarization $(V>V c)$, the viscoelastic solution flows from the Taylor cone and there is a reduction in electrostatic charge density on the surface of the jet. Taylor showed that $V c$ can be described as [37]:

$$
\left.\left(V c^{2}\right)^{2}=4\left(\frac{H^{2}}{L^{2}}\right)\left(\ln \frac{2 L}{R}\right)-1.5\right)(0.117 \pi R \gamma)
$$

where $V c$ is critical polarization, $H$ is distance of the needle to the collector, $L$ is length of the needle, $R$ is radius of the needle, and $\gamma$ is surface tension of the solution.

After crossing $V c$, the solution takes the form of a linear jet, being subjected to tension in the electric field (Figure 3).

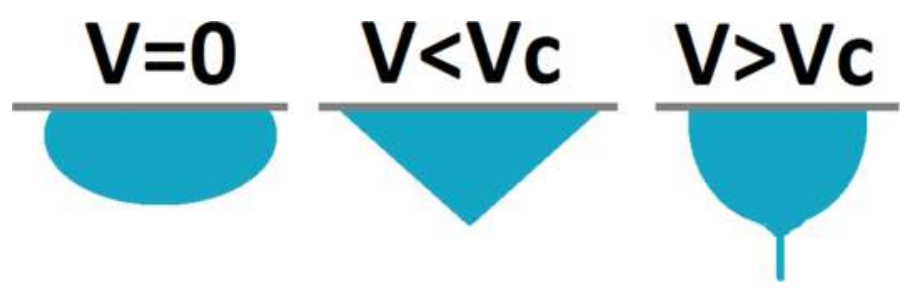

Figure 3. Changes in droplet shape under different forces, where $V$ is solution polarization and $V c$ is critical polarization.

\subsection{Rectilinear jet of the solution}

Zone of the rectilinear jet, leaving the "Taylor cone" is subjected to the electric field. Whereby the accumulation of electrostatic charges appears at the surface that causes the surface layer of the light polarization. In the layer of the surface of the solution, dipole (bipolar) layer electric 
is formed. This layer has always one type of charges facing toward the exterior surface and the other inside the jet.

Generated charged jet of the solution is defined by density of surface charges and electric potential. Aerial density of charges is varied along the length of the straight jet, due to Coulomb's law $[39,40]$.

In the fiber formation process, in a strong electrostatic field, the stretching of the jet reaches very high values. When the jet of the solution is straight, the stretching value is approximately 1000 times [39].

\subsection{Disabilities in the rectilinear jet}

Accumulated polarized charges on a straight stream interact with the generated electrostatic field and a specific wavelength stream is formed at the critical value of the electrostatic charge, initiating the formation of a large gradient flowing stream of the solution. Under these conditions, the release of internal cohesion trickles, and the solution begins to flow rapidly, causing turbulence of the straight section of the stream. The effect of turbulence is in the form of a cone. It changes the straight stream of traffic solution in a conical spiral motion that results from changes in the energy system. When the stream is subjected to bending, stretch reaches approximately 25,000 times [37].

\subsection{The spiral movement of the solution and solvent evaporation}

The spirals of the polymer solution are the result of exceeding the cohesive energy inside of the straight section of the stream by the value of the energy of the electrostatic field. As a result of these energy changes, the straight jet of the solution starts to form a cone of the spirals increasing in diameter.

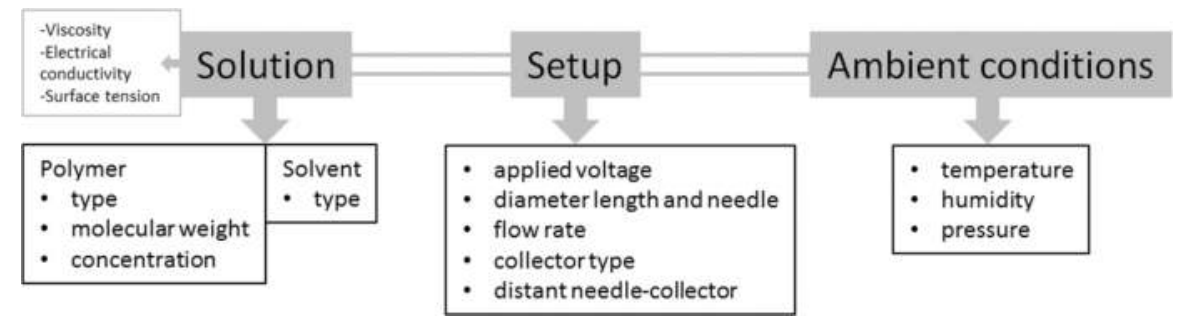

Figure 4. Influence of electrospinning process parameters on morphology and molecular structure.

Descriptions of the causes and effects of instability in a spiral cone spray can be found in many works by Reneker et al. [36, 41, 42].

About 15 main parameters of the process are distinguished. It is possible to divide them into three groups related with parameters of the process, setup, and ambient conditions (Figure 4). 
Morphology describes diameter, shape, porosity, topography of the single fiber surface and also pillarization (architecture), fiber association, total porosity of the patches. Morphology of single fibers and patches is mostly described in literature by scanning electron microscopy. Fibers formed in the electrospinning process are characterized by a diameter of 50-2000 nm. The mean fiber diameter depends on the polymer, solvent type, and equipment parameters (Figure 5) [11, 31]. Dry fibers, which are uniform in morphology, are electrospun in a narrow range of process parameters, called a window process. All parameters of the process have to be optimized to form beads-free uniform fibers [44].

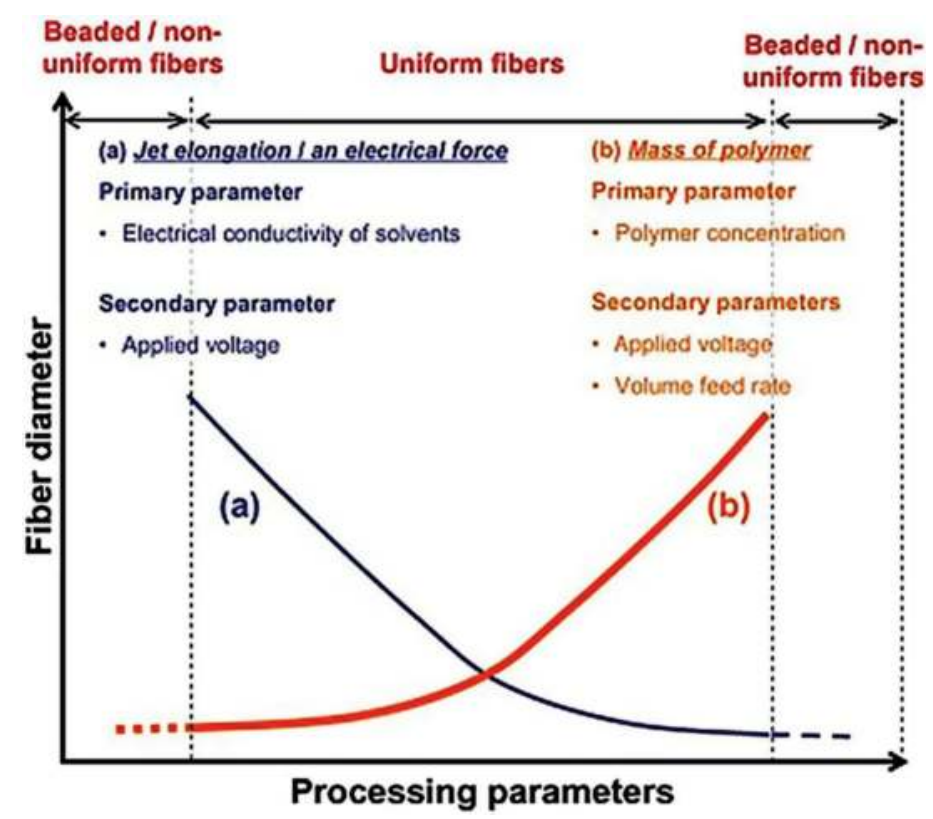

Figure 5. Fibers diameter as a function of the parameters related to (a) forces in solution jet and (b) polymer mass [10].

One of the first systematic descriptions of the influence of the process parameters on fiber morphology was prepared by Tan et al. [10].

In this simplification, parameters of the process were grouped into parameters which influence the jet elongation-electrical forces (blue line) and parameters which are related to the polymer mass (orange line). Each of them is divided into two individual groups: primary, exerting a stronger impact, and secondary, not playing such a significant role.

Primary parameters related to the polymer solution include electrical conductivity of the solvents and polymer concentration. Secondary parameters are related to applied voltage and flow rate. Generally, when impact of electrical conductivity of the solvent and applied voltage is lesser, thinner fibers are electrospun (smaller diameter); after achieving some maximum fibers with beads or only beads are formed. On the other hand, increase in polymer concen- 
tration, flow rate, and applied voltage contribute to smaller solution mass. As a consequence, thicker fibers are formed. Fibers with beads are formed when jet elongation is too effective or carried polymer mass is too low [45].

Deitzel et al. [45] reported that solution parameters had a stronger effect on fiber morphology than applied voltage. His observations overlapped with those of Ramakrishna et al., who found that too high applied voltage led to beads formation.

Results of the Thompson et al. model [31] indicate five parameters with a strong influence on the final diameter of the electrospinning jet, five parameters that have a moderate effect, and three parameters with only a minor effect on the fiber diameter. The most significant effect on the jet radius is exerted by volumetric charge density, distance from nozzle to collector, initial jet/orifice radius, relaxation time, and viscosity. The other parameters (initial polymer concentration, solution density, electric potential, perturbation frequency, and solvent vapor pressure) have a moderate effect on the jet radius. Parameters such as relative humidity, surface tension, and vapor diffusivity have a minor effect on the jet radius.

\section{Materials}

Biodegradable, synthetic polymers such as PCL, polylactic acid (PLA), polyglycolic acid (PGA) and their copolymers, less frequently used poly-3-hydroxybutyrate (PHB), polyurethane (PU) and natural polymers (biopolymers) are used in tissue engineering [4, 36]. Natural polymers like Col, Ge, Chit, elastin, silk, and keratin are commonly investigated. During the last few years, blends of synthetic polymers and biopolymers, or nanocomposites with nanoparticles ( $\mathrm{Au}, \mathrm{Ag}$, hydroxyapatite [41, 46], carbon nanotubes [42], etc.) have been formed to combine their properties and enhance functionality. To enhance biological properties, the fiber surface is modified by plasma, chemical assembly, growth factors, and drugs. Another trend is addition of encapsulated cells, viruses [47].

This chapter concentrates on an analysis of literature about electrospun polyester and blends of polyesters with biopolymers: Ge, Col, Chit. Polyester properties and chemistry are profoundly described in literature [33, 44].

$\mathrm{Col}$ is the most commonly used natural material for cartilage regeneration. In the native tissue, it represents $90 \%$ of the cartilage skeletal tissue. Col is a natural polymer with a triple helical structure which contains sequences enabling cell adhesion, migration, and differentiation [48]. Additionally, Col type II has a high amount of bound carbohydrate groups, allowing Col scaffold-water interaction. Col can be easily formed into various scaffold architectures. Most common forms analyzed and applied are gel [37, 43], sponges [49, 50], and fibers [51]. There are several scaffolds dedicated to tissues regeneration made from bovine Col type I (Ne Celsius degreesart, Histogenics Corporation, Waltham, MA) or rat-tail Col type I (CaReS-1S, ArthroKinetics, Esslingen, Germany) [52].

Ge is a natural polymer, a denatured form of Col. It is obtained by controlled hydrolysis of Col. Two types of Ge can be distinguished: Type A-extracted and processed by acidic pre- 
treatment from Col and Type B - obtained by alkaline pre-treatment [53]. Ge has been widely used because of its biological origin, biodegradability, biocompatibility, and commercial availability at a relatively low cost. The only disadvantage of Ge is its solubility in water without special treatment like cross-linking [54]. Nowadays, it has been used as sealant for vascular prostheses $[55,56]$, in drug delivery systems $[33,57,58]$ or dressings for wound healing $[59,60]$. Fiber and sponge forms are also obtained by various methods. Nevertheless, mixing Ge with other polymers, mostly synthetic polymers, is common practice $[22,61]$. Ge is already commercially used in wound dressings and as hemostatic sponges as well as bone scaffold (Comfeel Plus, Duoderm, Granuflex, Ultec, 3M Tegaderm Hydrocolloid; Gelfoam is also used [62].

Chit is a semi-crystalline polysaccharide polymer. It is produced commercially by deacetylation of chitin from skeletons of crustaceans (crabs, shrimp) and cell walls of fungi. Chit is found at least in $60 \%$ of deacetylated chitin [63]. Due to the high structural similarity to glycosaminoglycans, which build ECM of the cartilage tissue, it is commonly used in scaffolds for cartilage regeneration [64]. Its degradation products: chondroitin sulfate, dermatan sulfate, hyaluronic acid, keratin sulfate, and glycosylated type-II Col are nontoxic and they are easily involved in synthesis of articular cartilage. Positive charge of Chit macromolecules is responsible for some problems with electrospinning uniform fibers from its solutions. On the other hand, the positive charge of D-glucosamine residues in Chit helps in interaction with negatively charged compounds from the cell membrane, which has effect on analgesic activity and inhibition of RNA synthesis of microorganisms [65].Chit is commercially used for cartilage regeneration and wound healing [66].

\section{One component fibers}

Fibers electrospun from one polymer type are analyzed as a prospective material for tissue engineering applications. This summary concentrates mostly on PCL, as one of the most biocompatible, biodegradable, and promising polymers used in regenerative medicine. However, many papers about poly(ethylene oxide) (PEO) are also mentioned because it was the main demonstrator of the relationship between parameters of the electrospinning process and properties of the fibers formed.

\subsection{Solution parameters}

Type, concentration of the polymer, and solvent type determine the solution properties (density, boiling point, dipole moment, etc.). Those properties like viscosity, electrical conductivity, surface tension are critical for morphology and structure of electrospun single fibers and fiber patches.

Solution viscosity is highly related to polymer molecular chains entanglement; low polymer concentration and/or low molecular weight yield lacks chains engagements. As a consequence, lack of polymer chains in the jet attacks in opposition to surface tension attacks in 
opposition to surface tension. Because of that, beads (so-called Rayleigh instability) are formed. Critical chains engagement is necessary to form uniform fibres.

Solution viscosity depends on the polymer type, its concentration, and solvent type. Taking into account manure parameters, it is possible to obtain appropriate solution viscosity for effective electrospinning process $[3,67]$. Fong was one of the first people who described influence of viscosity on morphology of PEO fibers formed from aqua solution [12]. Beads were observed below defined viscosity, number of beads decreased with an increase in viscosity; the shape of beads changed from globular to spherical. After overrunning some critical value, bead-free fibers are formed. The diameter of uniform fibers changes with the polymer concentration.

The influence of the polymer concentration of aqueous PEO solutions on solution viscosity, surface tension, and diameter of electrospun fibers was evaluated [49]. Surface tension of the solution decreased with the polymer concentration, in opposition to the viscosity increase. However generally, the mean diameter of fibers increased with polymer concentration.

Molecular weight of a polymer also plays a significant role in formation of uniform fibers. PVA fibers electrospun from different molecular weight were analyzed. Electrospinning of low molecular weight PVA decide about electrospray forming and/or bead fibers formation [68].

Influence of molecular weight and polymer concentration on chains engagement was analyzed for some polymers and solution entanglement number (ne)s was determined [69].

$$
(\mathrm{ne}) s=\mathrm{Mw} /(\mathrm{Me}) \mathrm{s}
$$

where (Me)s is the entanglement molecular weight in solution, $\mathrm{Mw}$ is the weight-average molecular weight.
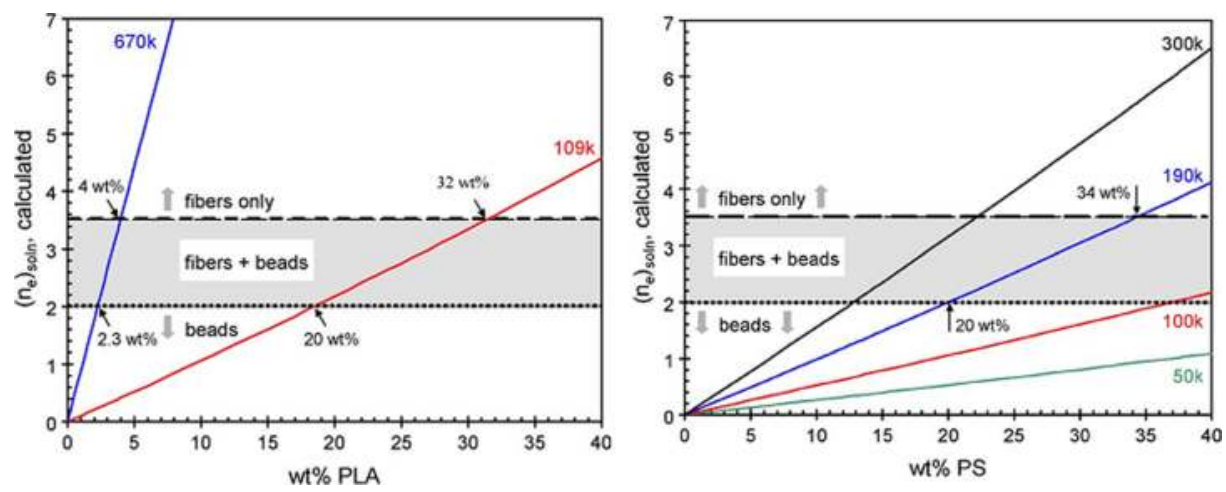

Figure 6. Fibers electrospinning in relations to solution entanglement number (ne)s and $\mathrm{Mw}$ in function of solution concentration (a) PLA and (b) PS [70]. 
Horizontal lines electrospray (beads), fibers with beads (fibers + beads) and fibers (Figures 6a and $\mathbf{6 b}$ ). Crosscut of the diagonal lines related to $\mathrm{Mw}$ of the polymer (blue, red, black, green) with horizontal lines (ne)s determines range of bead-free electrospun fibers. Examples: $\mathrm{Mw}$ $670 \mathrm{kDa}$ PLA below 4\%, Mw 109kDa PLA below 32\% uniform fibers were electrospun (Figure 6a).

PLA was electrospun from solutions differing in dichloromethane (DCM) concentration [71]. Viscosity and surface tension of the solution increased with polymer concentration; however, a decrease in electrical conductivity was recorded. Average fiber diameter and standard deviation of the diameter increased with the solution concentration. Analyses of electrical conductivity by pyridine additives were also performed.

Solution surface tension depends on the surface tension of the solvent, polymer concentration, and polymer molecular weight. Surface tension of the solution associated with low polymer concentration is usually higher than polymer chains engagement. Uniform distribution of the electrical charges possibly due to proper surface tension and viscosity (polymer concentration) enable formation of uniform fibers, free of beads [72]. Fiber diameter increases as a function of polyesters concentration. Electrical conductivity, dielectric constant, and viscosity enhance the effectiveness of forces applied to the solution [43].

Solutions characterized by relatively high electric conductivity carry more electrical charges during the electrospinning process. High charges density leads to effective stretching of the jet through repulsion of one sign charges. A highly conductive solvent eliminates high voltages during the process (deranging the process stability). Addition of DMF increases the solution conductivity; however, after exceeding a certain volume, beads are formed in the electrospinning process [73]. It is possible to enhance electrical conductivity by addition of polyelectric polymers with high electrical charge, like $\mathrm{Ge}$ and slats (e.g., $\mathrm{NaCl}$ ).

Dielectric constant supports formation of uniform fibers; however, similarly to electrical conductivity, too high dielectric constant leads to beads formation.

Windows process for some polyesters has been described in literature $[3,19,73]$.

Usually, round cross-section, ribbons or branched fibers are electrospun under certain conditions $[65,74]$. The phenomenon of formation of ribbon fibers was described using gelatin as an example. During rapid evaporation of the solvent from the surface of the jet, the skin is formed; under air pressure fibers are pressed and ribbons are formed [42].

On the surface of electrospun fibers, pores are formed. They influence chemical and physical properties (tension, wettability). Surface porosity arises from the solvent type or ambient conditions [75].

Fewer descriptions of the influence of electrospinning parameters on crystallinity and molecular structure have been found than on morphology.

Crystallinity of electrospun fibers and casted films was determined from wide-angle X-ray scattering (WAXS) data by Lee [76]. A higher degree of crystallinity was estimated for casted films than for fibers. Intensity of peaks from PCL crystals (I from 110/I from 200) of electro- 
spun Fibers was compered to peaks from casted films. Additionally, radial profiles of WAXS indicate partial orientation of PCL crystals along the fiber main axis in case of electrospun fibres.

Crystallinity was also diversified by different types of solvents. Thermal analyses, such as differential scanning calorimetry (DSC) and Raman spectroscopy, revealed lower crystallinity of PCL fibers electrospun from chloroform than from hexafluoroisopropanol (HFIP) [19]. The diameter of electrospun fibers, determined by properties of solvents, was not taken into account.

Influence of average $\mathrm{Mw}$ on molecular orientation was characterized using PVA as an example [77]. WAXS data indicate higher molecular orientation of PVA fibers electrospun from polymers characterized by higher molecular weight. It correlates with increase of crystallinity of fibers electrospun from PVA with higher Mw.

By optical microscopy (dark field), optical birefringence of PEO electrospun fibers was determined [78]. Degree of birefringence was not analyzed. In another publication, ordering of polymer macromolecules in the direction of the electric field was found in the needle [79].

Morphology and molecular structure of a single electrospun fiber influences mechanical properties.
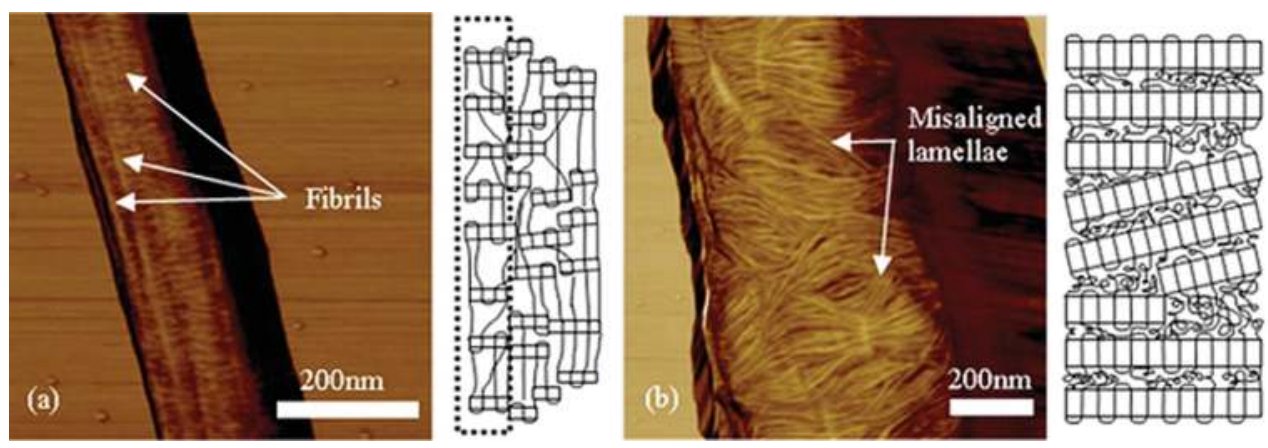

Figure 7. PCL fibers illustrated by AFM, electrospun from 10\% solutions (a) $150 \mathrm{~nm}$ and (b) $450 \mathrm{~nm}$ [81].

Nanometric PCL fibers indicate higher Young's modulus than submicron ones [80]. It was observed that thin fibers (electrsopun from solution with low concentrations) were characterized by higher crystallinity than submicron fibers. It is opposite to publications which suggest increase in crystallinity with polymer concentration (fiber diameter). Authors suspect increase in molecular orientation with fiber diameter. Fibril structure of nanometric fibers and lamellar structure of submicron fibers was illustrated by atomic force microscopy (AFM) (Figures 7a \& Figures $7 \mathbf{b}$ ). Fibrils consist of staggered crystal and amorphous phases; lamellas consist of densely located lamellas and non-oriented amorphous phase.

Young's modulus of single fibers was analyzed in nanoindentanion mode by AFM for PLLA, PCL, Col fibers [82]. Analyses indicate higher Young's modulus of nanometric fibers than 
submicron ones [83]. It can be related to the higher order of chains in thin fibers and smooth surface.

Young's modulus decreases with fiber diameter, the increase in fiber diameter is observed for fibers electrospun from PCL solutions with concentration from 10-14 wt\% [81]. In the same publication, significant elongation at break increase is observed with an increase in polymer concentration. These observations are confirmed on PVA [84]. Young's modulus determined from AFM in nanoindentation mode indicates decreased stiffness in fiber diameter. The analysis was performed for solution with $8 \%$ concentration. For polyvinylidene fluoride (PVDF) and PCL fibers, a decrease of Young's modulus as a function of diameter was observed [85].

\subsection{Setup parameters}

One of the most significant parameters in electrospinning process is applied voltage. Applied voltage regulates charges to the solution droplet. Density of the applied voltage, as value of applied charges on the surface of the droplet is described by applied voltage, distance between the needle and collector, and solution conductivity. It has to be related to the solvent type and polymer concentration.

Demir et al. [39] used polyurethane fibers and noticed that jet diameter increased with applied voltage; however, threshold voltage (necessary for start of the process) strongly depends on solution concentration [86].

Influence of applied voltage on the fiber diameter was found for PCL fibers electrospun from HFIP solution. Fiber diameter increases with same maximum value for fibers electrospun with different applied voltages in range of 7-20 kV [40].

Description of the applied voltage influence on crystallinity was not found for polyesters. Crystallinity as a function of applied voltage was found for cellulose fibers electrospun on plate [11]. Analyses indicate an increase of crystallinity with voltage, followed by a decrease of crystallinity after achieving a certain maximum value. It is explained as a result of powerful dynamics of crystallinity in high voltage which falters after the critical voltage is exceeded by longer distance fibers falling down.

Volume expansion of the solution is regulated by the flow rate settled by a medical pump. Flow rate is critical in Taylor cone formation; as a consequence of too fast flow rate, beads are formed, in the case of too slow flow rate, the needle clogs [15, 70].

Length nozzle optimization was also described. With the length of needles, polymer chains orientation increases in the jet and standard deviation of diameter of electrospun fibers decreases [87].

An appropriate distance between the needle and collector enables solvent evaporation which also strongly influences the fiber morphology (single, not agglomerated fibers).

Fibers from poly(hydroxybutyrate-co-hydroxyvalerate) (PHBV) were electrospun using positive applied (PV) and negative applied voltage (NV) [88]. In both PV and NV, it was found 
that the fiber diameter generally increased with increasing the solution concentration and increasing inner diameter but decreased with increasing the working distance, while the solution feeding rate did not significantly affect the fiber diameter. However, the fiber diameter increased with increasing PV but decreased with increasing NV. Polarity of the applied voltage did not significantly affect the water contact angle, which suggests no influence on the chemical structure of fibers. In the case of polyamide 11, changes of surface chemistry were observed while comparing fibers electrospun using NV and PV [76].

The architecture of electrospun patches depends on the collector type. Usually, fibers are electrospun on plates, drums, wires, and grids. Porosity of the patches may be changed by using different types of collectors [18]. Fibers electrospun on plate are of a random architecture, fibers electrospun on a drum are orientated in the direction of the drum rotation. Degree of fiber polarization is regulated by the speed of drum rotation and applied voltage $[9,89]$. Fibers collected on drum have lower diameter than those collected on plate because of stretching during collecting (provided other parameters remain constant).

Porosity of electrospun fibers is within $60-92 \%$, with the size of a single pore within the range of $1-465 \mu \mathrm{m}$ [90].

Intensity of peaks registered by WAXS of PLLA fibers change depending on polymer concentration and degree of stretching; increase in molecular orientation and crystallinity was found as a function of degree of stretching (comparison: $63 \mathrm{~m} / \mathrm{min}$ and $630 \mathrm{~m} / \mathrm{min}$ ) [15]. Peaks intensity increases with concentration, additionally with fibers annealing.

Molecular orientation of PAN electrspun fibers increases with the speed of drum rotation of $0-12.3 \mathrm{rot} / \mathrm{min}$. Tailoring the rotation speed makes it possible to electrospin fibers of demanded molecular orientation [91]. High-speed rotation also guarantees paralyzation of electrospun fibers.

Mechanical analyses of electrospun fibers and patches are performed using AFM and traditional stress-strain equipment like INSTRON. The latter is more related to whole patches than single fibers. Typically, Young's modulus and maximum strain are determined. Differences in calculation arise from consulting real fibers amount on the sample cross-section.

In general, fibers collected on a drum display higher strength than those collected on a plate, which is related to molecular orientation of fibers collected on a drum [40].

\subsection{Ambient conditions}

Temperature plays a significant role during solvent evaporation. Time of crystallization decreases with the rising temperature which correlates with a weaker degree of crystallinity in the shorter time $[3,40]$. Changes of temperature also lead to fiber porosity [15].

Air humidity has an effect on electrical conductivity of the ambient environment. Fiber diameter decreases with humidity when we change it from 30-50\% [3]. Relatively low applied voltage and high viscosity can be used in $50 \%$ of humidity. Changes of humidity also influence surface porosity of a single fiber [92]. 
Usually, the electrospinning process takes place in air atmosphere; however, electrospinning in atmospheres of different gases is possible.

Temperature and humidity are not strictly controlled, as a consequence not so many researches describe influence of these parameters on fiber morphology and structure.

\section{Bicomponent fibers with Col, Ge, and Chit}

In the last few years, some literature has confirmed positive influence of biopolymer additive on the functionality of electrospun patches in tissue engineering applications. Most common biopolymers added to synthetic polymers are $\mathrm{Col}, \mathrm{Ge}$, and Chit.

\subsection{Fibers with $\mathrm{Col}$ and $\mathrm{Ge}$}

Biopolymer additives to polyester influence the morphology as well as molecular and supermolecular structures of electrospun fibers. This part of description concentrates on blends with Ge and Col. Synthetic/biopolymer w/w\% ratio is a subsequent parameter of the solution parameters group.

A decrease in fiber diameter was observed as a function of applied biopolymer or poly-lacticco-glycolic acid (PLGA)/Ge and poly(lactide-co-e-glycolic acid) (PLCL)/Ge blends [93]. Additionally, smaller fiber diameter and pore size of the patches electrospun on a drum in comparison to fibers collected on a plate were seen.

From the viewpoint of tissue engineering application (in-vitro and in-vivo study), miscibility (compatibility) of both polymers or interactions of their chemical groups seem to be important. Literature about miscibility of biopolymer and polyesters is sketchy and inconsistent.

Phase separation of Ge/PCL (1:1) in tetrafluoroethylene (TFE) and its consequences on electrospun fibers were analyzed by Feng et al [81,94] and continued by Xue et al. [95]. Fluorescence observation of the FITC-conjugated Ge/PCL/TFE solution and dynamic light scattering (DSL) methods confirm the phase separation in the mixed solution. Phase separation leads to electropsun fibers splashing, bonding, and distribution in fiber diameter. Small addition of acetic acid to solution was found to lead to the opaque solution becoming transparent immediately without occurrence of precipitation for over 1 week. Nanofibers formed from solution with acetic acid are thinner, smoother, and more uniform. Increase in tensile strength and decrease in strain at break in fibers electrospun without acetic acid was observed [96].

Miscibility of polymer depends on glass temperature Tg. It is known that Tg value of miscible blends is between the values of those for both components [97]. In immiscible blends, two separate Tg values are observed [98].

$\mathrm{Tg}$ is usually determined from DSC data. However, it depends on the ambient temperature and humidity, so changes are not always connected exclusively with both components' 
miscibility. Euna et al. [99] describes strong influence of water on $\mathrm{Tg}$ of $\mathrm{Ge}$. Tg of some blends within effect from crystal melting of one component PCL/Ge (Tg of Ge about $48^{\circ} \mathrm{C}$ ), which impedes miscibility analyses from $\mathrm{Tg}$.

Zhang et al. observed phase separation in PCL/Ge blends electrospun from TFE. As a consequence of leaching, pores on the surface of electrospun fibers appeared [100].

Phase separation was observed for PLLA/Ge in the analyses. Observation by transmission electron microscopy (TEM) illustrated Ge phase located along fiber axes (Figure 8) [86].
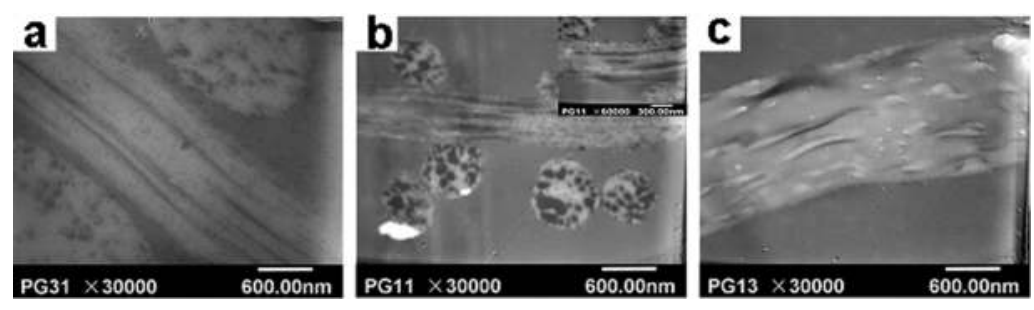

Figure 8. TEM observations of PLLA/Ge. (a) 3:1, (b) 1:1, and (c) 1:3 [101].

Fourier Transform Infrared Spectroscopy (FTIR) analyses of the Chit-PEO fibers indicate modified spectrum (between both polymers) [102].

In the article, Electro-spinning of pure collagen nano-fibers - Just an expensive way to make Ge?, polar solvent denaturants helixes structure of peptides are shown. HFIP, TFE probably destroy weak hydrogen bonds related to helixes structure [103].

DSC curves for PCL in PCL/Ge blends indicate overlapping of signals from both components (PCL, Ge) and dependence of PCL crystallinity on solvent type [19]. Crystallinity of PCL in PCL/Ge 50:50 from HFIP and TFE data was found to be 0.20 and 0.25 , respectively. Miscibility of PCL/ Ge blends analysed from WAXS data was proved by shifts of peaks from PCL crystals (shifts of 110, 200).

Molecular orientation also changes with addition of Ge to PCL, as was observed on drumcollected fibers [79]. PCL crystallinity increases in the presence of a small amount of Ge.

In patches functioning as 3D cells scaffolds, wettability plays a significant role. Polyesters are hydrophobic, the contact angle of PCL is $109^{\circ}$ [104], Ge $76^{\circ}$ [105], Col 50. PCL/Ge, PLGA/Ge blends show higher wettability than pure polymers, the contact angle is within $0-20^{\circ}$ [72]. Lack of additives of this parameter has not been clearly explained in literature. In some publications, it is described as a result of ordering nonpolar groups of polymer in proximity of synthetic polymer; in some others, ionization of Ge is considered to play a significant role.

\subsection{Fibers with Chit}

Solution prepared from pure Chit and 90\% acetic acid showed an increase in viscosity with higher Chit concentration. Uniform fibers are easily electrospun for Mn $106 \mathrm{kDa}$; for $30 \mathrm{kDa}$, 
the engagement of chains was too small, so beads were formed, for $398 \mathrm{kDa}$, driven mass was too high to be driven by applied voltage, so again beads were formed [106]. Electrospinning window process of Chit dissolved in acid aqueous solution was determined by Vrieze et al. [107]. Optimal values of electrospinning parameters to form uniform fibers are Chit concentration of $3 \%$, concentration of acetic acid of $90 \%$, collector-needle distance of $10 \mathrm{~cm}$, solution flow rate of $0.3 \mathrm{cml} / \mathrm{h}$, applied voltage of $20 \mathrm{kV}$. Use of these parameters leads to the formation of uniform fibers, with a diameter of $70 \pm 45 \mathrm{~nm}$.

In the case of PCL/Chit blends, an increase of conductivity was observed with an addition of Chit to PCL [108], as a consequence, an increase in the diameter of fibers electrospun from blends in comparison to those from pure PCL was observed.

Chen et al. analyzed changes of diameter as a function of PLCL/Chit (1:1 mol \%) concentration and ratio of PLCL/Chit [109]. Analyses indicate a decrease in the fiber diameter in the first case, and a decrease in diameter with aggregate polymers concentration. Increase of porosity and pore size was observed with Chit to PLCL additive. The porosity of patches electrospun from blends decreased in the case of collection-oriented fibers (drum collector) in comparison to fibers collected randomly on a plate or grid [131].

Peaks observed on FTIR spectra of PCL/Chit fibers, at 1675 and $1530 \mathrm{~cm}^{-1}$ correspond to the stretching of amide and protonated amine groups resulting from residual trifluoroacetic acid (TFA), as was also reported by Sangsanoh and Supaphol [110]. Spectra indicate that there is no miscibility between PCL/Chit chains, so no covalent bonding between the polymers occurred [111, 112]. The authors suggested that only physical interactions, such as the intermolecular hydrogen bonding between the carbonyl group of PCL and hydroxyl or ammonium ions of Chit between the Chit and PCL, remained. PCL/Chit fibers incubated in cell culture media for two weeks did not swell. This capability of retaining structural integrity in an aqueous environment confirms interaction of chains, possibly by engagement of Chit chains by PCL macromolecules.

XPS data confirm differences in surface analyses of blend electrospun using NV and PV applied to the needle [107].

Fibers electrospun from pure Chit are fully amorphous; polyesters and copolymers usually display crystallinity. WAXS observations indicate that blends elctrospun from PLCL/Chit (1:1) exhibit less crystallinity than pure electrospun PLCL. It suggests that Chit destroyed most of the regular arrangements of PLCL [131].

In the case of PCL/Chit blends, the intensity of the higher peak tends to decrease with the increase in the Chit weight content [113]. It is also evident that the peak position shifts to a smaller angle with the addition of Chit. It has been demonstrated that the conjugation of PCL with Chit suppresses the crystallization of both Chit and PCL to a certain extent. It has also been suggested that Chit and PCL chains are well mixed at a molecular level.

Decrease in tensile stress and ultimate strain and stiffness with Chit to PLCL [131], PCL addition was observed [135]. 
Pure Chit is hydrophilic (contact angle of about $67^{\circ}$, while polyesters are usually hydrophobic. Contact angle of PCL/Chit blend fibers increases from $109^{\circ}$ for PCL/Chit 3:1 to $82^{\circ}$ for $1: 3$ blend [135].

\section{Biological investigation on one- and bicomponent electrospun fibers}

In general, the product dedicated to use in tissue engineering should provide a repeatable and long lasting effect on treated tissue. Because of that, scaffolds should fulfill the following conditions connected with their functionality and the manufacturing process:

a. Biocompatible and bioresorbable;

b. Three-dimensional (3D) form which encourages formation of tissue;

c. Highly porous structure; interconnected/permeable pore network;

d. Mechanical properties suitable for application;

e. Controllable degradation rates;

f. Surface chemistry suitable for cellular attachment, proliferation; good connection with the surrounding tissues;

g. Production of scaffold should be easy and give repeatable results;

h. Prepared product should be easy in application; and

i. Price of the product should be affordable.

Electrospinning process is flexible enough to fulfill all of these requirements. Fibers from biocompatible, biodegradable polymers are easily prepared; additionally, it is possible to tailor their morphology, architecture, mechanical properties, etc., by electrospinning process parameters (paragraph 2-3). Electrospun patches exhibit many similarities in architecture and porosity degree to natural ECM.

Influence on fiber morphology modulated by PCL concentration and applied voltage was described [11]. PCL fibers electrospun from 8, 15, 20\% HFIP solution exhibit increased fibroblast proliferation which correlates with an increase in diameter as a function of concentration. Influence of applied voltage changes in time: increase of proliferation with voltage after 3 days, increase after 6 days. Negative influence of beads on cell proliferation was observed.

Analyses of cellular response indicate a complex relationship between the diameter of fibers electrospun from PCL tailored by solution concentration (8-20\%) and cell proliferation [96]. Beaded structures prevent cellular proliferation, indicating the need for uniform fibers for tissue-engineering scaffolds. Maximum positive effect of fiber diameter was observed for fibers with a diameter of $400 \mu \mathrm{m}$.

Electrospun patches showed a relatively small size of single pores. Pores facilitate cell migration and transport [114]. Porosity of PCL patches can be expanded by appropriate 
collectors up to 10 times [90]. Cell migration increases with total porosity and pore size, unfortunately publications about the degree of changes were not found.

Some tissues display a parallel arrangement of cells and ECM fibers (muscle, heart). It was the impulse for the formation of scaffolds with parallel arrangement of fibers. Drums and parallel wires are used for that purpose. For instance, in tendons and ligaments, stretch forces are 200500 times higher in the fiber direction (forces generation) than perpendicular to this direction [115]. In cartilage joints, forces on the core are higher on the surface, and the highest in the direction of the main Col fiber [99]. It is another reason to analyze and mimic the nature; core fibers are formed as a consequence.

Increase of proliferation and migration was observed in PCL patches with a single pore size enhanced to about $50 \mu \mathrm{m}$ [116]. Additionally, cell migration was supported by "layer by layer" technique, in which fiber spinning and cell seeding is held layer by layer.
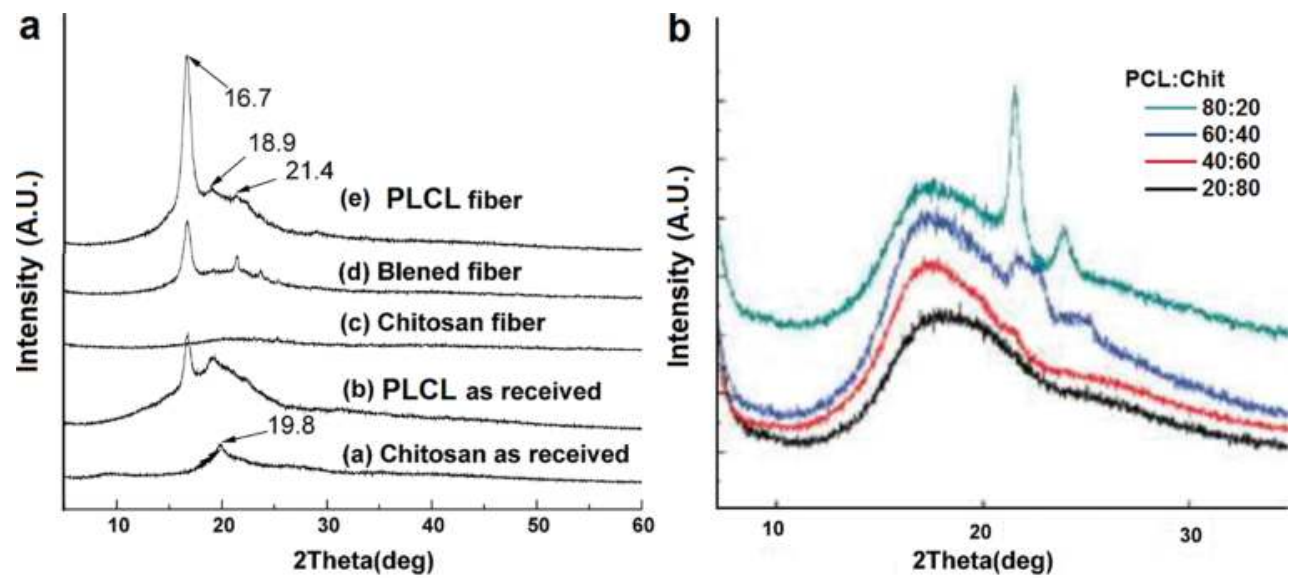

Figure 9. WAXS radial profile of (a) PLCL, Chit and PLCL/Chit 1:1 [131] and (b) PCL/Chit blends with different ratios [135].

Schwann cells seeded on PCL patches indicate parallelization in the direction of fibers. It is the sign of interaction scaffolds-cell, described in literature as a contact guidance (Figure 9) [101].

Analyses of the polyester/biopolymer blends influence on patches functionality are usually related to the arbitrally adopted ratio of the biopolymer about $20 / 30 \%$.

The only publication found describes PLCL/Ge patches, electrospun from solutions of 100:0, 90:10, 70:30, 50:50, 30:70, and 0:100 [113]. A decrease in fiber diameter was observed as a function of the Ge amount (Figure 10), increase in total porosity (from 52 to 74\%) and Young's modulus. Miscibility of PLC/Ge was determined from DSC data, and it was found that 90:10 was miscible, while other blends were immiscible. 
Neural stem cells (C17.2) seeded on PCL, PCL/Ge 70:30 patches indicate higher activity determined by mitochondrial activity test after 2, 4, and 6 days on drum-collected patches (oriented fibres) than on plate (random fibres) [117]. It is described as a result of high hydrophilicity of PCL/Ge patches and contact guidance on oriented patches-cells skeleton elongated along the fiber direction.
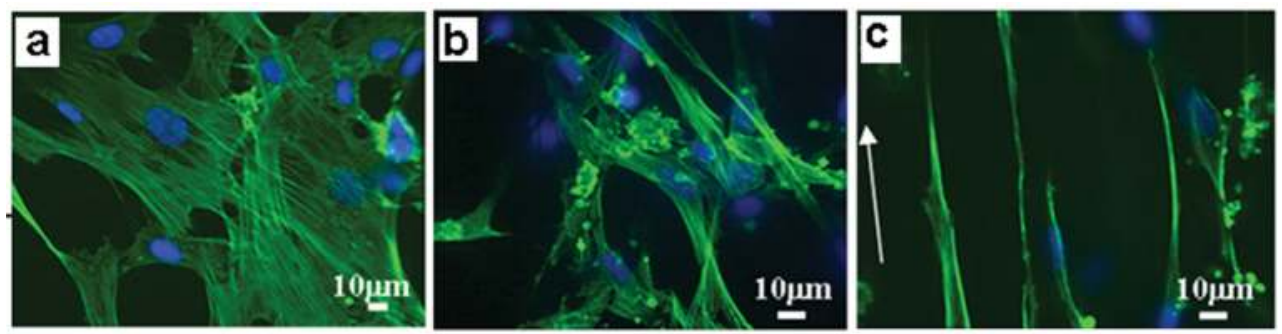

Figure 10. Observations by fluorescence microscopy after 7 days, cells seeded on (a) control, (b) non-oriented fibers, and (c) oriented (parallel) fibers [142].

Nerve cells seeded on PLCL/Col patches indicate higher activity on patches with Col type I and III than with Col I additive. Contact guidance on oriented patches was observed [5].

Cancer cells seeded on PCL, PCL/Ge patches were also analyzed by Hartman et al. [19]. Addition of Ge to PCL supports functionality, as scaffolds are more effective when HFIP is used as a solvent than TFE. A decrease in diameter and increase in Young's modulus were observed as a function of additive.

Decryption of cells differentiation on polyester blends with Ge or Col is picked up rarely. However, stem cells differentiation to nerve is more effective on PCL/Col patches than with those polymers electrospun separately [118]; (PCL/Ge 50:50 patches were taken into account).

PCL/Ge 7:3 blend electrospun on a drum displays higher Young's modulus and less mass lost during 12 weeks degradation than patches electrospun on a plate (random) [119]. Proliferation degree was higher on fibers electrospun on a drum, which correlates with higher Young's modulus.

Pure Chit electrospun from 70:30 v/v TFA/DCM (trifluoroacetic acid/dichloromethane) was analyzed as a substrate toward Schwann cells, osteoblast, keratinocyte, and fibroblast cells viability, proliferation spreading [117]. Viability and proliferation of osteoblasts cultivated on Chit fibers was highest in comparison to TCP and other cells types. Osteoblasts were also the most spread in comparison to the other cells analyzed.

Human adipose-derived stem cells (hASCs) indicate better proliferation on PCL/Ge 1:1 with addition of bone powder than on pure PCL/Ge [120].

That indicates that additional natural bioactivator enhances the cellular response. PCL/Chit blends, containing various amounts of Chit $(0,3,9$, and 23\%) were electrospun and evaluat- 
ed for their osteogenic differentiation of preosteoblasts [135]. Osteoblasts cultivated on PCL/ Chit exhibit calcium deposition, alkaline phosphatase (ALP) activity, and the expression of osteopontin (OPN). Culture of cell-rich 3D constructs prepared by assembling cells layer-bylayer on PCL/Chit nanofibers led to a uniform tissue formation with significant mineralization at 21 days.

Patches electrospun from PCL/Chit solution were designed and evaluated in-vitro using rat Schwann cells for nerve tissue engineering [121]. Investigations indicate smaller mean diameter of blended fibers than pure polymers as follows: 630, 450, and $190 \mathrm{~nm}$, respectively, for PCL, Chit, PCL/Chit blend, where PCL/Chit scaffolds fabricated using an electrospinning process showed better cell proliferation than PCL scaffolds and maintained their characteristic cell morphology, with spreading bipolar elongations to the nanofibrous substrates.

Post-treatment by cross-linking of PCL-gelatin, PLGA-gelatin, PLGA-Chit tubes was analyzed in case of cytotoxicity [122]. All patches showed about $5 \%$ increase in toxicity after cross-linking by glutaraldehyde. However, other analyses confirm higher liquid strength of cross-linked scaffolds than non-cross-linked scaffolds. It was a consequence of superior mechanical properties of a cross-linked scaffold and a decrease of pore size.

\section{Conclusions}

Nowadays, fibers formed in electrospinning process are commercially available in many branches of industry, including regenerative medicine and tissue engineering. Electrospinning is a success story, one of the very few belonging to the broad area of nanotechnologies which hold so great, unprecedented promises. Understanding of electrospinning process parameters enables tailoring of electrospun nanofibers morphology, internal structure, and properties. This opens up new possibilities for the use of fibers and improves the solutions already produced on the basis of electrospun fibers.

Mammal cells are sensitive enough to respond even to small changes in the above parameters as well as to changes in the chemical structure. Cellular attachment, proliferation, differentiation occur at the surface of the fiber through the interaction of polymer molecules with the adhesion proteins (focal adhesion) found on the cellular surface. Use of electrospun nanofibers in tissue engineering is also driven by process flexibility and similarities in architecture to natural ECM. Different morphology, architecture, porosity, and alternative polymers with bio-activators are combined easily in the electrospinning process. Additionally, low cost of fiber production accompanies the aforementioned advantages.

Regulations applicable to scaffolds (medical devices) are restrictive, so the commercialization process is usually long in this case. However, tailoring of fiber composition appropriate for the application and cooperation with companies specializing in the industrial upscaling of electrospinning process are a guaranty of the success like in the case of Tegaderm, 3M Medical, TranCyte, Dermagraft-TC, Chito-Flex, Integra, etc., for wound dressing. 


\section{Acknowledgements}

This work was supported by grants: 2013/09/D/ST8/04009 from the Polish National Centre of Sciences and 388/L-6/2014 from the The National Centre for Research and Development.

\section{Author details}

\section{Dorota Kołbuk}

Address all correspondence to: dkolbuk@ippt.pan.pl

Institute of Fundamental Technological Research, Polish Academy of Sciences, Warsaw, Poland

\section{References}

[1] Luo CJ, Stoyanov SD, Stride E, Pelan E, Edirisinghe M. Electrospinning versus fibre production methods: from specifics to technological convergence. Chem Soc Rev. 2012;41(13):4708. DOI: 10.1039/c2cs35083a

[2] Cort JR, Andersen NH. Formation of a molten-globule-like state of myoglobin in aqueous hexafluoroisopropanol. Biochem Biophys Res Commun. 1997;233(3):687-91. DOI: $10.1006 /$ bbrc.1997.6524

[3] Ramakrishna S, Fujihara K, Teo W-E, Lim T-C, Ma Z. An Introduction to Electrospinning and Nanofibers. World Scientific Pub Co Pte Lt; 2005. p. 396. DOI: 10.1142/9789812567611

[4] Kijeńska E, Prabhakaran MP, Swieszkowski W, Kurzydlowski KJ, Ramakrishna S. Electrospun bio-composite P(LLA-CL)/collagen I/collagen III scaffolds for nerve tissue engineering. J Biomed Mater Res. 2012;21;100B(4):1093-102. DOI: 10.1002/jbm.b.32676

[5] Doshi J, Reneker DH. Electrospinning process and applications of electrospun fibers. In: Proceedings of the IEEE Industry Applications Conference Twenty-Eighth IAS Annual Meeting; 2-8 October 1993; Toronto, Ontario. New York: 1993. p. 1698-1703. DOI: 10.1109/ias.1993.299067

[6] Langer R, Vacanti J. Tissue engineering. Science. 1993;14;260(5110):920-6. DOI: 10.1126/ science. 8493529

[7] Sell SA, Wolfe PS, Garg K, McCool JM, Rodriguez IA, Bowlin GL. The use of natural polymers in tissue engineering: a focus on electrospun extracellular matrix analogues. Polym. 2010;9:522-53. DOI: 10.3390/polym2040522 
[8] Cui W, Zhou Y, Chang J. Electrospun nanofibrous materials for tissue engineering and drug delivery. Sci Technol Adv Mater. 2010;11(1):014108. http://dx.doi.org/ 10.1088/1468-6996/11/1/014108

[9] Bhardwaj N, Kundu SC. Electrospinning: a fascinating fiber fabrication technique. Biotech Adv. 2010;28(3):325-47. DOI: 10.1016/j.biotechadv.2010.01.004

[10] Tan S-H, Inai R, Kotaki M, Ramakrishna S. Systematic parameter study for ultra-fine fiber fabrication via electrospinning process. Polym. 2005;46(16):6128-34. DOI: 10.1016/ j.polymer.2005.05.068

[11] Zhao S, Wu X, Wang L, Huang Y. Electrospinning of ethyl-cyanoethyl cellulose/ tetrahydrofuran solutions. J Appl Polym Sci. 2003;91(1):242-6. DOI: 10.1002/app.13196.

[12] Salem DR. Electrospinning of nanofibers and the charge injection method, In: Brown PJ, Stevens K, editors. Nanofibers and Nanotechnology in Textiles. Cambridge: Woodhead; 2007. p. 3-21. DOI: 10.1533/9781845693732

[13] Hartman O, Zhang C, Adams EL, Farach-Carson MC, Petrelli NJ, Chase BD, et al. Biofunctionalization of electrospun PCL-based scaffolds with perlecan domain IV peptide to create a 3-D pharmacokinetic cancer model. Biomat. 2010;31(21):5700-18. DOI: 10.1016/j.biomaterials.2010.03.017.

[14] Ding B, Kim H-Y, Lee S-C, Shao C-L, Lee D-R, Park S-J, et al. Preparation and characterization of a nanoscale poly(vinyl alcohol) fiber aggregate produced by an electrospinning method. J Polym Sci, B: Polym Physics. 2002;20;40(13):1261-8. DOI: 10.1002/ polb.10191

[15] Kim CH, g YH, Kim HY, Lee DR, Dharmaraj N, Choi KE. Effect of collector temperature on the porous structure of electrospun fibers. Macromol Res. 2006;14(1):59-65. DOI: $10.1007 /$ bf03219069

[16] Cui H, Sinko PJ. The role of crystallinity on differential attachment/proliferation of osteoblasts and fibroblasts on poly (caprolactone-co-glycolide) polymeric surfaces. Front Mat Sci. 2011;7;6(1):47-59. DOI: 10.1007/s11706-012-0154-8

[17] Balasundaram G, Sato M, Webster TJ. Using hydroxyapatite nanoparticles and decreased crystallinity to promote osteoblast adhesion similar to functionalizing with RGD. Biomat. 2006;27(14):2798-805. DOI: 10.1016/j.biomaterials.2005.12.008

[18] Yaylaoglu M. Development of a calcium phosphate-gelatin composite as a bone substitute and its use in drug release. Biomat. 1999;20(8):711-9. DOI: 10.1016/ s0142-9612(98)00199-9

[19] Woodruff MA, Hutmacher DW. The return of a forgotten polymer-Polycaprolactone in the 21st century. Prog Polym Sci. 2010;35(10):1217-56. DOI: 10.1016/j.progpolymsci.2010.04.002

[20] Sambudi NS, Sathyamurthy M, Lee GM, Park SB. Electrospun chitosan/poly(vinyl alcohol) reinforced with $\mathrm{CaCO} 3$ nanoparticles with enhanced mechanical properties 
and biocompatibility for cartilage tissue engineering. Comp Sci Tech. 2015;106:76-84. DOI: 10.1016/j.compscitech.2014.11.003

[21] Kim M, Kim GH. Electrohydrodynamic direct printing of PCL/collagen fibrous scaffolds with a core/shell structure for tissue engineering applications. Chem Eng J. 2015;279:317-26. DOI: 10.1016/j.cej.2015.05.047

[22] Kołbuk D, Sajkiewicz P, Maniura-Weber K, Fortunato G. Structure and morphology of electrospun polycaprolactone/gelatine nanofibres. Eur Polym J. 2013;49(8):2052-61. DOI: 10.1016/j.eurpolymj.2013.04.036

[23] Rayleigh, Lord. XX. On the equilibrium of liquid conducting masses charged with electricity. Philosl Mag, 5. 1882;14(87):184-6. DOI: 10.1080/14786448208628425

[24] Zeleny J. Instability of Electrified Liquid Surfaces. Phys Rev. 1917;10(1):1-6. DOI: 10.1103/physrev.10.1

[25] Dole M. Molecular Beams of Macroions. J Chem Phys. 1968;49(5):2240. DOI: $10.1063 / 1.1670391$

[26] Drozin VG. The electrical dispersion of liquids as aerosols. J Coll Sci. 1955;10(2):15864. DOI: 10.1016/0095-8522(55)90022-2

[27] Anton F. Process and Apparatus for Preparing Artificial Threads. U.S. Patent No 1,975,504, 1934.

[28] Larrondo L, St. John Manley R. Electrostatic fiber spinning from polymer melts. II. Examination of the flow field in an electrically driven jet. J Polym Sci Polym Phys Ed. 1981;19(6):921-32. DOI: 10.1002/pol.1981.180190602

[29] Larrondo L, St. John Manley R. Electrostatic fiber spinning from polymer melts. III. Electrostatic deformation of a pendant drop of polymer melt. J Polym Sci Polym Phys Ed. 1981;19(6):933-40. DOI: 10.1002/pol.1981.180190603

[30] Yarin AL, Koombhongse S, Reneker DH. Bending instability in electrospinning of nanofibers. J Appl Phys. 2001;89(5):3018. DOI: 10.1063/1.1333035

[31] Thompson CJ, Chase GG, Yarin AL, Reneker DH. Effects of parameters on nanofiber diameter determined from electrospinning model. Polym. 2007;48(23):6913-22. DOI: 10.1016/j.polymer.2007.09.017

[32] Persano L, Camposeo A, Tekmen C, Pisignano D. Industrial upscaling of electrospinning and applications of polymer anofibers: a review. Macromol Mater Eng. 2013;8;298(5):504-20. DOI: 10.1002/mame.201200290.

[33] Iwata T, Yoshiharu D. Crystal structure and biodegradation of aliphatic polyester crystals. Macromol Chem Phyis. 1999;200;11:2429-2442. DOI: 10.1002/(SICI)1521-3935(19991101)200:11<2429::AID-MACP2429>3.0.CO;2-\# 
[34] Teo WE, Ramakrishna S. A review on electrospinning design and nanofibre assemblies. Nanotech. 2006;30;17(14):R89-R106. DOI: 10.1088/0957-4484/17/14/r01

[35] Srivastava $Y$, quez M, Thorsen T. Multijet electrospinning of conducting nanofibers from microfluidic manifolds. J Appl Polym Sci. 2007;14;106(5):3171-8. DOI: 10.1002/ app. 26810

[36] Liu CZ, Czernuszka JT. Development of biodegradable scaffolds for tissue engineering: a perspective on emerging technology. Mat Sci Tech. 2007;23(4):379-91. DOI: $10.1179 / 174328407 \times 177027$

[37] Kawamura S, Wakitani S, Kimura T, Maeda A, Caplan AI, Shino K, et al. Articular cartilage repair: rabbit experiments with a collagen gel-biomatrix and chondrocytes cultured in it. Acta Orthop Scand. 1998;69(1):56-62. DOI: 10.3109/17453679809002358

[38] Garg K, Bowlin GL. Electrospinning jets and nanofibrous structures. Biomicrofluidics. 2011;5(1):013403. DOI: 10.1063/1.3567097

[39] Demir M., Yilgor I, Yilgor E, Erman B. Electrospinning of polyurethane fibers. Polym. 2002;43(11):3303-9. DOI: 10.1016/s0032-3861(02)00136-2

[40] Kolbuk D, Guimond-Lischer S, Sajkiewicz P, Maniura-Weber K, Fortunato G. The effect of selected electrospinning parameters on molecular structure of polycaprolactone nanofibers. Int J Polym Mat Polym Biomat. 2014;2;64(7):365-77. DOI: 10.1080/00914037.2014.945209

[41] Ryszkowska JL, Auguścik M, Sheikh A, Boccaccini AR. Biodegradable polyurethane composite scaffolds containing Bioglass ${ }^{\circledR}$ for bone tissue engineering. Comp Sci Tech. 2010;70(13):1894-908. DOI: 10.1016/j.compscitech.2010.05.011

[42] Zhu Y, Li C, Cebe P. Poly(lactides) co-electrospun with carbon nanotubes: thermal and cell culture properties. Eur Polym J. 2016;75:565-76. DOI: 10.1016/j.eurpolymj. 2016.01.014.

[43] Kimura T, Yasui N, Ohsawa S, Ono K. Chondrocytes embedded in collagen gels maintain cartilage phenotype during long-term cultures. Clin Orthop Relat Res. 1984;186:231-9. DOI: 10.1097/00003086-198406000-00039.

[44] Idaszek J, Bruinink A, Święszkowski W. Delayed degradation of poly(lactide-coglycolide) accelerates hydrolysis of poly( $\varepsilon$-caprolactone) in ternary composite scaffolds. Polym Degrad Stability. 2016;124:119-27. DOI: 10.1016/j.polymdegradstab. 2015.12.020

[45] Deitzel J., Kleinmeyer J, Harris D, Beck Tan N. The effect of processing variables on the morphology of electrospun nanofibers and textiles. Polym. 2001;42(1):261-72. DOI: 10.1016/s0032-3861(00)00250-0

[46] Auguścik M, Prociak A, Rojek P, Ryszkowska J. Polyurethane-urea substrates from rapeseed oil-based polyol for bone tissue cultures intended for application in tissue 
engineering. Polym Deg Stab. 2014;108:241-9. DOI: 10.1016/j.polymdegradstab. 2014.03.010

[47] Salalha W, Kuhn J, Dror Y, Zussman E. Encapsulation of bacteria and viruses in electrospun nanofibres. Nanotech. 2006;30;17(18):4675-81. DOI: $10.1088 / 0957-4484 / 17 / 18 / 025$

[48] Kleinman HK. Role of collagenous matrices in the adhesion and growth of cells. J Cell Biol. 1981;1;88(3):473-85. DOI: 10.1083/jcb.88.3.473

[49] Speer DP, Chvapil M, Vorz RG, Holmes Md. Enhancement of Healing in Osteochondral Defects by Collagen Sponge Implants. Clin Orthop Relat; 1979;144:326-335. DOI: 10.1097/00003086-197910000-00056.

[50] Lu H, Ko Y-G, Kawazoe N, Chen G. Cartilage tissue engineering using funnel-like collagen sponges prepared with embossing ice particulate templates. Biomat. 2010;31(22):5825-35. DOI: 10.1016/j.biomaterials.2010.04.019

[51] Teuschl AH, Nürnberger S, Redl H, Nau T. Articular cartilage tissue regenerationcurrent research strategies and outlook for the future. Eur Surg. 2013;45(3):142-53. DOI: 10.1007/s10353-013-0217-9

[52] Irion VH, Flanigan DC. New and Emerging Techniques in Cartilage Repair: Other Scaffold-Based Cartilage Treatment Options. Operat Sports Med. 2013;21(2):125-37. DOI: 10.1053/j.otsm.2013.03.001

[53] Zhou P, Regenstein JM. Effects of Alkaline and Acid Pretreatments on Alaska Pollock Skin Gelatin Extraction. J Food Sci. 2005;70(6):c392-c396. DOI: 10.1111/j. 1365-2621.2005.tb11435.x

[54] Zhang Y, Ouyang H, Lim CT, Ramakrishna S, Huang Z-M. Electrospinning of gelatin fibers and gelatin/PCL composite fibrous scaffolds. J Biomed Mater Res. 2004;72B(1): 156-65. DOI: 10.1002/jbm.b.30128

[55] Guidoin R, ceau D, Rao TJ, King M, Merhi Y, Roy P-E, et al. In vitro and in vivo characterization of an impervious polyester arterial prosthesis: the Gelseal Triaxial ${ }^{\circledR}$ graft. Biomat. 1987;8(6):433-41. DOI: 10.1016/0142-9612(87)90079-2

[56] Marois Y, Chakfé N, Deng X, Marois M, How T, King MW, et al. Carbodiimide crosslinked gelatin: a new coating for porous polyester arterial prostheses. Biomat. 1995;16(15):1131-9. DOI: 10.1016/0142-9612(95)93576-y

[57] Li JK, Wang N, Wu XS. Gelatin nanoencapsulation of protein/peptide drugs using an emulsifier-free emulsion method. J Microencap. 1998;15(2):163-72. DOI: $10.3109 / 02652049809006846$

[58] Cortesi R, Nastruzzi C, Davis SS. Sugar cross-linked gelatin for controlled release: microspheres and disks. Biomat. 1998;19(18):1641-9. DOI: 10.1016/ s0142-9612(98)00034-9 
[59] Choi YS, Hong SR, Lee YM, Song KW, Park MH, Nam YS. Study on gelatin-containing artificial skin: I. Preparation and characteristics of novel gelatin-alginate sponge. Biomat. 1999;20(5):409-17. DOI: 10.1016/s0142-9612(98)00180-x

[60] Ulubayram K. EGF containing gelatin-based wound dressings. Biomat. 2001;1;22(11): 1345-56. DOI: 10.1016/s0142-9612(00)00287-8

[61] Kim H-W, Yu H-S, Lee H-H. Nanofibrous matrices of poly(lactic acid) and gelatin polymeric blends for the improvement of cellular responses. J Biomed Mater Res. 2008;87A(1):25-32. DOI: 10.1002/jbm.a.31677

[62] Rohanizadeh R, Swain MV, Mason RS. Gelatin sponges (Gelfoam) as a scaffold for osteoblasts. J Mat Sci: Mat Med. 2007;15;19(3):1173-82. DOI: 10.1007/s10856-007-3154$\mathrm{y}$

[63] Croisier F, Jérôme C. Chitosan-based biomaterials for tissue engineering. Eur Polym J. 2013;49(4):780-92. DOI: 10.1016/j.eurpolymj.2012.12.009

[64] Neves SC, Moreira Teixeira LS, Moroni L, Reis RL, Van Blitterswijk CA, Alves NM, et al. Chitosan/Poly(๑-caprolactone) blend scaffolds for cartilage repair. Biomat. 2011;32(4):1068-79. DOI: 10.1016/j.biomaterials.2010.09.073

[65] Stanishevsky AV, Wetuski JD, Yockell-Lelièvre H. Crystallization and stability of electrospun ribbon- and cylinder-shaped tungsten oxide nanofibers. Ceramics Int. 2016;42(1):388-95. DOI: 10.1016/j.ceramint.2015.08.122

[66] Charernsriwilaiwat N, Rojanarata T, Ngawhirunpat T, Sukma M, Opanasopit P. Electrospun chitosan-based nanofiber mats loaded with Garcinia mangostana extracts. Int J Pharm. 2013;452(1-2):333-43. DOI: 10.1016/j.ijpharm.2013.05.012

[67] Kolbuk D, Guimond-Lischer S, Sajkiewicz P, Maniura-Weber K, Fortunato G. The effect of selected electrospinning parameters on molecular structure of polycaprolactone nanofibers. Int J Polym Mater Polym Biomat. 2014;2;64(7):365-77. DOI: 10.1080/00914037.2014.945209

[68] Tao J, Shivkumar S. Molecular weight dependent structural regimes during the electrospinning of PVA. Mater Letters. 2007;61(11-12):2325-8. DOI: 10.1016/j.matlet. 2006.09.004

[69] Shenoy SL, Bates WD, Frisch HL, Wnek GE. Role of chain entanglements on fiber formation during electrospinning of polymer solutions: good solvent, non-specific polymer-polymer interaction limit. Polym. 2005;46(10):3372-84. DOI: 10.1016/ j.polymer.2005.03.011

[70] Mo X, Xu C, Kotaki M, Ramakrishna S. Electrospun P(LLA-CL) nanofiber: a biomimetic extracellular matrix for smooth muscle cell and endothelial cell proliferation. Biomat. 2004;25(10):1883-90. DOI: 10.1016/j.biomaterials.2003.08.042 
[71] Zeng J, Haoqing H, Schaper A, Wendorff JH, Greiner A. Poly-L-lactide nanofibers by electrospinning - Influence of solution viscosity and electrical conductivity on fiber diameter and fiber morphology. e-Polym. 2003;1;3(1). DOI: 10.1515/epoly.2003.3.1.102

[72] Mit-uppatham C, Nithitanakul M, Supaphol P. Ultrafine electrospun polyamide-6 fibers: effect of solution conditions on morphology and average fiber diameter. Macromol Chem Phy. 2004;26;205(17):2327-38. DOI: 10.1002/macp.200400225

[73] Lee KH, Kim HY, Khil MS, Ra YM, Lee DR. Characterization of nano-structured poly( $\varepsilon-$ caprolactone) nonwoven mats via electrospinning. Polym. 2003;44(4):1287-94. DOI: 10.1016/s0032-3861(02)00820-0

[74] Koombhongse S, Liu W, Reneker DH. Flat polymer ribbons and other shapes by electrospinning. J Polym Sci, B: Polym Phys. 2001;39(21):2598-606. DOI: 10.1002/polb. 10015

[75] Lubasova D, tinova L. Controlled morphology of porous polyvinyl butyral nanofibers. J Nanomat. 2011;2011:1-6. DOI: 10.1155/2011/292516

[76] Stachewicz U, Stone CA, Willis CR, Barber AH. Charge assisted tailoring of chemical functionality at electrospun nanofiber surfaces. J Mater Chem. 2012;22(43):22935. DOI: $10.1039 / \mathrm{c} 2 \mathrm{jm} 33807 \mathrm{f}$

[77] Ding B, Kim H-Y, Lee S-C, Shao C-L, Lee D-R, Park S-J, et al. Preparation and characterization of a nanoscale poly(vinyl alcohol) fiber aggregate produced by an electrospinning method. J Polym Sci, B: Polym Phys. 2002;20;40(13):1261-8. DOI: 10.1002/ polb.10191

[78] Reneker DH, Yarin AL, Zussman E, Xu H. Electrospinning of nanofibers from polymer solutions and melts. Adv Appl Mech. 2007;43-346. DOI: 10.1016/ s0065-2156(07)41002-x

[79] Greenfeld I, Arinstein A, Fezzaa K, Rafailovich MH, Zussman E. Polymer dynamics in semidilute solution during electrospinning: simple model and experimental observations. Phys Rev E. 2011;84(4). DOI: 10.1103/physreve.84.041806

[80] Lim CT, Tan EPS, Ng SY. Effects of crystalline morphology on the tensile properties of electrospun polymer nanofibers. Appl Phys Lett. 2008;92(14):141908. DOI: $10.1063 / 1.2857478$

[81] Feng B, Duan H, Fu W, Cao Y, Jie Zhang W, Zhang Y. Effect of inhomogeneity of the electrospun fibrous scaffolds of gelatin/polycaprolactone hybrid on cell proliferation. J Biomed Mater Res. 2014;9;103(2):431-8. DOI: 10.1002/jbm.a.35184

[82] Tan EPS, Lim CT. Nanoindentation study of nanofibers. Appl Phys Letters. 2005;87(12): 123106. DOI: $10.1063 / 1.2051802$

[83] Tan EPS, Ng SY, Lim CT. Tensile testing of a single ultrafine polymeric fiber. Biomat. 2005;26(13):1453-6. DOI: 10.1016/j.biomaterials.2004.05.021 
[84] Cheng Q, Wang S. A method for testing the elastic modulus of single cellulose fibrils via atomic force microscopy. Compos, A: Appl Sci Manufac. 2008;39(12):1838-43. DOI: 10.1016/j.compositesa.2008.09.007

[85] Gao K, Hu X, Dai C, Yi T. Crystal structures of electrospun PVDF membranes and its separator application for rechargeable lithium metal cells. Mat Sci Eng, B. 2006;131(1-3): 100-5. DOI: 10.1016/j.mseb.2006.03.035

[86] Yang X, Xu Q, Yan N, Sui G, Cai Q, Deng X. Structure and wettability relationship of coelectrospun poly (L-lactic acid)/gelatin composite fibrous mats. Polym Adv Tech. 2010;18;22(12):2222-30. DOI: 10.1002/pat.1749

[87] Wang C, Cheng Y-W, Hsu C-H, Chien H-S, Tsou S-Y. How to manipulate the electrospinning jet with controlled properties to obtain uniform fibers with the smallest diameter? - a brief discussion of solution electrospinning process. J Polym Res. 2010;17;18(1):111-23. DOI: 10.1007/s10965-010-9397-1

[88] Tong H-W, Wang M. Electrospinning of fibrous polymer scaffolds using positive voltage or negative voltage: a comparative study. Biomed Mat. 2010;28;5(5):054110. DOI: $10.1088 / 1748-6041 / 5 / 5 / 054110$

[89] Li D, Ouyang G, McCann JT, Xia Y. Collecting electrospun nanofibers with patterned electrodes. Nano Lett. 2005;5(5):913-6. DOI: 10.1021/n10504235

[90] Thorvaldsson A, Stenhamre H, Gatenholm P, Walkenström P. Electrospinning of highly porous scaffolds for cartilage regeneration. Biomacromol. 2008;9(3):1044-9. DOI: $10.1021 / \mathrm{bm} 701225 \mathrm{a}$

[91] Fennessey SF, Farris RJ. Fabrication of aligned and molecularly oriented electrospun polyacrylonitrile nanofibers and the mechanical behavior of their twisted yarns. Polym. 2004;45(12):4217-25. DOI: 10.1016/j.polymer.2004.04.001

[92] Casper CL, Stephens JS, Tassi NG, Chase DB, Rabolt JF. Controlling surface morphology of electrospun polystyrene fibers: effect of humidity and molecular weight in the electrospinning process. Macromol. 2004;37(2):573-8. DOI: 10.1021/ma0351975

[93] Lee J, Tae G, Kim YH, Park IS, Kim S-H, Kim SH. The effect of gelatin incorporation into electrospun poly(l-lactide-co-๑-caprolactone) fibers on mechanical properties and cytocompatibility. Biomat. 2008;29(12):1872-9. DOI: 10.1016/j.biomaterials.2007.12.029

[94] Feng B, Tu H, Yuan H, Peng H, Zhang Y. Acetic-acid-mediated miscibility toward electrospinning homogeneous composite nanofibers of GT/PCL. Biomacromol. 2012;10;13(12):3917-25. DOI: 10.1021/bm3009389

[95] Xue J, He M, Liu H, Niu Y, Crawford A, Coates PD, et al. Drug loaded homogeneous electrospun PCL/gelatin hybrid nanofiber structures for anti-infective tissue regeneration membranes. Biomat. 2014;35(34):9395-405. DOI: 10.1016/j.biomaterials. 2014.07.060 
[96] Chen M, Patra PK, Warner SB, Bhowmick S. Role of fiber diameter in adhesion and proliferation of NIH $3 \mathrm{~T} 3$ fibroblast on electrospun polycaprolactone scaffolds. Tissue Eng. 2007;13(3):579-87. DOI: 10.1089/ten.2006.0205

[97] Bower DI. An Introduction to Polymer Physics. Cambridge University Press; 2002. p. 343-356. DOI: 10.1017/cbo9780511801280

[98] Gil ES, Frankowski DJ, Bowman MK, Gozen AO, Hudson SM, Spontak RJ. Mixed protein blends composed of gelatin and bombyx $\mathrm{m}$ ori silk fibroin: effects of solventilnduced crystallization and composition. Biomacromol. 2006;7(3):728-35. DOI: 10.1021/bm050622i

[99] Zhang S. Fabrication of novel biomaterials through molecular self-assembly. Nat Biotech. 2003;21(10):1171-8. DOI: 10.1038/nbt874

[100] Zhang YZ, Feng Y, Huang Z-M, Ramakrishna S, Lim CT. Fabrication of porous electrospun nanofibres. Nanotech. 2006;16;17(3):901-8. DOI: 10.1088/0957-4484/17/3/047

[101] Chew SY, Mi R, Hoke A, Leong KW. The effect of the alignment of electrospun fibrous scaffolds on Schwann cell maturation. Biomat. 2008;29(6):653-61. DOI: 10.1016/ j.biomaterials.2007.10.025

[102] Duan B, Dong C, Yuan X, Yao K. Electrospinning of chitosan solutions in acetic acid with poly(ethylene oxide). J Biomat Sci, Polym Ed. 2004;15(6):797-811. DOI: $10.1163 / 156856204774196171$

[103] Zeugolis DI, Khew ST, Yew ESY, Ekaputra AK, Tong YW, Yung L-YL, et al. Electrospinning of pure collagen nano-fibres - Just an expensive way to make gelatin? Biomat. 2008;29(15):2293-305. DOI: 10.1016/j.biomaterials.2008.02.009

[104] Ghasemi-Mobarakeh L, Prabhakaran MP, Morshed M, Nasr-Esfahani M-H, Ramakrishna S. Electrospun poly(๑-caprolactone)/gelatin nanofibrous scaffolds for nerve tissue engineering. Biomat. 2008;29(34):4532-9. DOI: 10.1016/j.biomaterials.2008.08.007

[105] Sajkiewicz P, Kołbuk D. Electrospinning of gelatin for tissue engineering - molecular conformation as one of the overlooked problems. J Biomat Sci, Polym Ed. 2014;30;25(18):2009-22. DOI: 10.1080/09205063.2014.975392

[106] Geng X, Kwon O, g J. Electrospinning of chitosan dissolved in concentrated acetic acid solution. Biomat. 2005;26(27):5427-32. DOI: 10.1016/j.biomaterials.2005.01.066

[107] De Vrieze S, Westbroek P, Van Camp T, Van Langenhove L. Electrospinning of chitosan nanofibrous structures: feasibility study. J Mat Sci. 2007;15;42(19):8029-34. DOI: 10.1007/s10853-006-1485-6

[108] Van der Schueren L, De Meyer T, Steyaert I, Ceylan Ö, Hemelsoet K, Van Speybroeck $\mathrm{V}$, et al. Polycaprolactone and polycaprolactone/chitosan nanofibres functionalised 
with the pH-sensitive dye Nitrazine Yellow. Carbohydrate Polym. 2013;91(1):284-93. DOI: 10.1016/j.carbpol.2012.08.003

[109] Chen F, Li X, Mo X, He C, Wang H, Ikada Y. Electrospun chitosan-P(LLA-CL) nanofibers for biomimetic extracellular matrix. J Biomat Sci, Polym Ed. 2008;19(5):677-91. DOI: $10.1163 / 156856208784089661$

[110] Sangsanoh P, Supaphol P. Stability improvement of electrospun chitosan nanofibrous membranes in neutral or weak basic aqueous solutions. Biomacromol. 2006;7(10): 2710-4. DOI: 10.1021/bm0602861

[111] Elzein T, Nasser-Eddine M, Delaite C, Bistac S, Dumas P. FTIR study of polycaprolactone chain organization at interfaces. J Coll Inter Sci. 2004;273(2):381-7. DOI: 10.1016/ j.jcis.2004.02.001

[112] Pawlak A, Mucha M. Thermogravimetric and FTIR studies of chitosan blends. Thermochim Acta. 2003;396(1-2):153-66. DOI: 10.1016/s0040-6031(02)00523-3

[113] Yang X, Chen X, Wang H. Acceleration of osteogenic differentiation of preosteoblastic cells by chitosan containing nanofibrous scaffolds. Biomacromol. 2009;12;10(10): 2772-8. DOI: 10.1021/bm900623j

[114] Khorshidi S, Solouk A, Mirzadeh H, Mazinani S, Lagaron JM, Sharifi S, et al. A review of key challenges of electrospun scaffolds for tissue-engineering applications. J Tissue Eng Regen Med. 2015;n/a-n/a. DOI: 10.1002/term.1978

[115] Lee JH, g HW, Kang I-K, Lee HB. Cell behaviour on polymer surfaces with different functional groups. Biomat. 1994;15(9):705-11. DOI: 10.1016/0142-9612(94)90169-4

[116] Hong JK, Madihally SV. Three-dimensional scaffold of electrosprayed fibers with large pore size for tissue regeneration. Acta Biomat. 2010;6(12):4734-42. DOI: 10.1016/ j.actbio.2010.07.003

[117] Sangsanoh P, Suwantong O, Neamnark A, Cheepsunthorn P, Pavasant P, Supaphol P. In vitro biocompatibility of electrospun and solvent-cast chitosan substrata towards Schwann, osteoblast, keratinocyte and fibroblast cells. Eur Polym J. 2010;46(3):428-40. DOI: 10.1016/j.eurpolymj.2009.10.029

[118] Hackett JM, Dang TT, Tsai EC, Cao X. Electrospun biocomposite polycaprolactone/ collagen tubes as scaffolds for neural stem cell differentiation. Mater. 2010;19;3(6):371428. DOI: $10.3390 / \mathrm{ma} 3063714$

[119] Kuppan P, Sethuraman S, Krishnan UM. Interaction of human smooth muscle cells with nanofibrous scaffolds: Effect of fiber orientation on cell adhesion, proliferation, and functional gene expression. J Biomed Mater Res. 2014;5;103(7):2236-50. DOI: 10.1002/jbm.a.35360 
[120] Rong D, Chen P, Yang Y, Li Q, Wan W, Fang X, et al. Fabrication of gelatin/PCL electrospun fiber mat with bone powder and the study of its biocompatibility. 2016;4;7(1):6. DOI: 10.3390/jfb7010006

[121] Prabhakaran MP, Venugopal JR, Chyan TT, Hai LB, Chan CK, Lim AY, et al. Electrospun biocomposite nanofibrous scaffolds for neural tissue engineering. Tissue Engg, A. 2008;14(11):1787-97. DOI: 10.1089/ten.tea.2007.0393

[122] Nguyen T-H, Lee B-T. The effect of cross-linking on the microstructure, mechanical properties and biocompatibility of electrospun polycaprolactone-gelatin/PLGAgelatin/PLGA-chitosan hybrid composite. Sci Technol Adv Mater. 2012;1;13(3):035002. DOI: 10.1088/1468-6996/13/3/035002

[123] Liu H, Hsieh Y-L. Ultrafine fibrous cellulose membranes from electrospinning of cellulose acetate. J Polym Sci, B: Polym Phys 2002;8;40(18):2119-29. DOI: 10.1002/polb. 10261 
